\title{
AVALIAÇÃO DA SECAGEM DAS FATIAS E FRAÇÕES DO LIMÃO TAHITI (CITRUS LATIFOLIA - TANAKA)
}

\author{
A. SILVA $^{1}$, F. B. FREIRE ${ }^{1}$, e M. C. FERREIRA ${ }^{1}$ \\ ${ }^{1}$ Universidade Federal de São Carlos, Departamento de Engenharia Química \\ E-mail de contato: mariaf@ufscar.br
}

\begin{abstract}
RESUMO - O limão é um fruto heterogêneo, formado por três frações distintas, sendo elas o epicarpo (casca externa), o mesocarpo (camada branca) e o endocarpo (polpa com gomos e vesículas contendo seu suco). O objetivo deste trabalho é analisar a secagem de fatias do limão e também de cada uma das frações (casca, mesocarpo e polpa) isoladamente, já que a desidratação de cada fração ocorre com diferentes taxas de transporte de massa. Os ensaios de secagem foram conduzidos em estufa, sob temperaturas de $50{ }^{\circ} \mathrm{C}$ e $60{ }^{\circ} \mathrm{C}$. Verificou-se que o endocarpo fatiado foi a fração que isoladamente apresentou taxas de secagem mais altas, em comparação com o epicarpo e mesocarpo. A secagem das fatias apresentou cinética mais lenta do que as das partes individuais. Nas condições avaliadas, o aumento da temperatura de $50{ }^{\circ} \mathrm{C}$ para $60{ }^{\circ} \mathrm{C}$ provocou redução de aproximadamente $33 \%$ no tempo requerido para a secagem das fatias.
\end{abstract}

\section{INTRODUÇÃO}

A secagem em grande escala de produtos do gênero alimentício, empregando o ar quente é uma operação unitária amplamente utilizada na indústria. A secagem, se feita de forma adequada, resulta em produtos com condições propícias de armazenagem por maiores tempos em relação ao produto in-natura, pois a retirada da umidade contida nos alimentos reduz a incidência de microrganismos e a deterioração. A lima ácida Tahiti (Citrus latifolia - Tanaka), conhecida popularmente como limão Tahiti, possui diversas aplicações culinárias, onde se sobressai o uso como condimento, aromatizante ou acidulante, e especialmente no preparo de alimentos cozidos ou saladas, e de limonadas. É utilizado, ainda, para prevenir o escurecimento em frutas frescas e em conservas vegetais devido à presença de ácido cítrico e em xaropes, devido à presença da vitamina C. Na medicina alternativa é usado tanto para o tratamento de problemas gastrointestinais, quanto contra infecções bacterianas. As frutas cítricas, em especial os limões, já eram consumidos desde a antiguidade pelos seus benefícios medicinais na prevenção e cura do escorbuto, doença causada pela deficiência de ácido ascórbico (Ziena, 2000; Viana, 2010; Millezi et al., 2013).

O limão possui três frações distintas que compõe sua estrutura, cada uma com composição química e características específicas, como mostra a Figura 1. 


\section{9 a 22 de outubro de 2014 \\ Florianópolis/SC}

Epicarpo: rico em vitaminas, carotenóides e óleos essenciais.

Mesocarpo: composto por hemicelulose, celulose, lignina, glicídios solúveis, substâncias pécticas e compostos fenólicos.

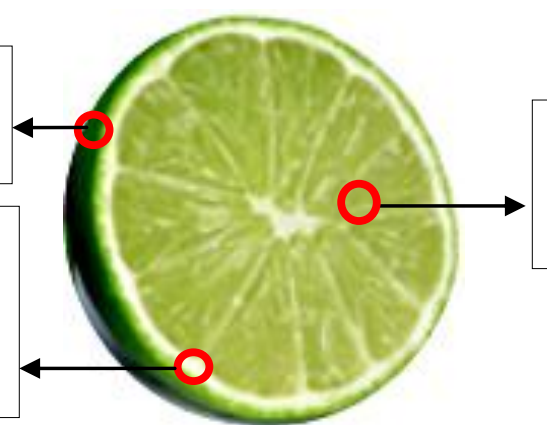

Endocarpo ou polpa: suco rico em sais minerais, vitamina $\mathrm{C}$ e ácido cítrico.

Figura 1 - Estrutura do limão e seus principais constituintes.

No Brasil a fruta é consumida predominantemente in natura, diferente de muitos países da Europa, Ásia e também da América do Norte, onde é comum o comércio da fruta seca inteira ou em fatias, na forma de pó, e cascas granuladas em diferentes granulometrias, tanto para uso comercial como doméstico, com aplicações diretas na culinária e indústrias alimentícias.

O limão é composto por partes com diferentes composições, que formam um conjunto estruturado. A secagem em fatias é conveniente, já que tal processo aplicado ao fruto inteiro além de demandar tempo maior, pode levar a um produto final de qualidade inferior. Devido à heterogeneidade na composição das fatias, uma análise adequada da cinética de secagem requer o estudo das cinéticas das partes individuais. Assim, o presente trabalho tem como objetivo analisar a secagem de fatias do limão Tahiti e também a secagem de cada uma das frações (casca, mesocarpo e polpa) isoladamente, visando avaliar as taxas de remoção de umidade das fatias e das diferentes frações. Os ensaios foram efetuadas nas temperaturas de $50{ }^{\circ} \mathrm{C}$ e $60{ }^{\circ} \mathrm{C}$.

\section{MATERIAIS E MÉTODOS}

A matéria prima utilizada nos experimentos são os frutos do limão Tahiti (Citrus Latifolia Tanaka). Os frutos foram coletados sempre em um mesmo estabelecimento da cidade de São Carlos-SP, e, antes do procedimento, passaram por higienização com água potável, para eliminação de impurezas.

Para o corte das fatias foi utilizado um processador de alimentos doméstico, que produzia fatias com espessura média de $2,4 \mathrm{~mm}$. As frações do limão (epicarpo e mesocarpo) foram separadas manualmente com a ajuda de uma faca de cozinha. O endocarpo teve a casca totalmente removida e foi fatiado também com uma faca de cozinha. Os gomos foram separados formando pedaços triangulares. Foram selecionadas as amostras com espessura média de 2,5 mm, aferida com um paquímetro digital (precisão de 0,01 mm). Fotos de amostras das fatias inteiras, epicarpo, mesocarpo e endocarpo fatiado são mostradas na Figura 2. Para avaliar possíveis influências nos resultados devido às diferenças na composição do material, foram feitos 2 ensaios com cada condição usando amostras adquiridas em dias diferentes. A secagem das amostras de cada parte mencionada foi executada nas temperaturas de 50 e $60{ }^{\circ} \mathrm{C}$. 

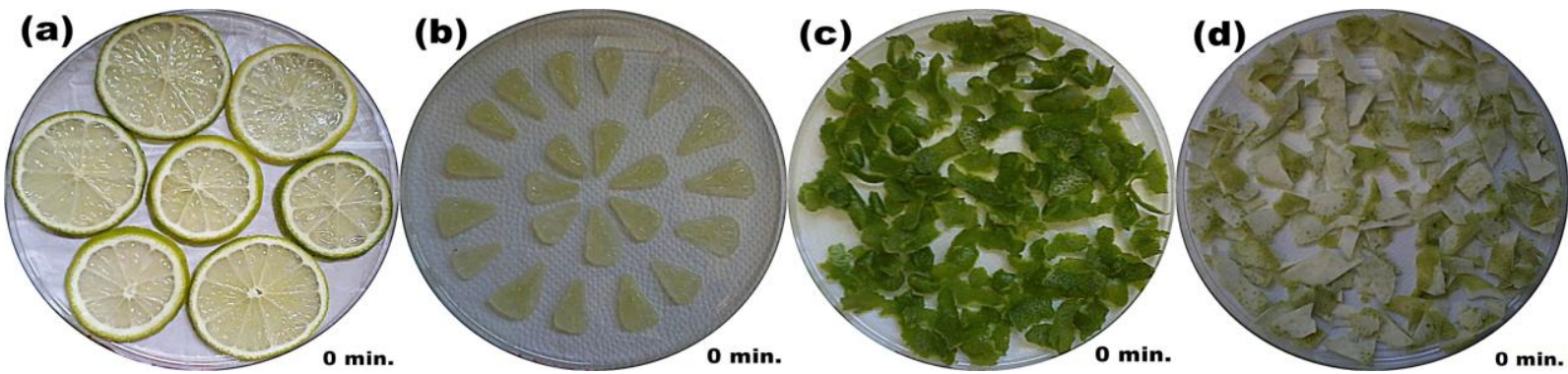

Figura 2 - Frações do limão utilizadas nos ensaios de secagem, (a) fatias, (b) endocarpo fatiado, (c) epicarpo e (d) mesocarpo.

Os experimentos foram realizados utilizando-se uma estufa sem circulação forçada de ar, da marca Tecnal, modelo TE-394/1, com controlador eletrônico da temperatura interna. Para a verificação de variação de massa dos materiais durante os ensaios, foi utilizada uma balança semianalítica marca GEHAKA, modelo BK440 (precisão 0,001 g). As massas foram aferidas até que atingissem a massa constante ao final de cada processo de secagem. Com os dados coletados foram calculados a razão adimensional de umidade e a taxa de secagem, por meio das Equações 1 e 2 respectivamente:

$$
\begin{gathered}
M R=\frac{X_{t}-X_{e q}}{X_{0}-X_{e q}} \\
T X=\frac{X_{t+d t}-X_{t}}{d t}
\end{gathered}
$$

\section{RESULTADOS E DISCUSSÃO}

Na Tabela 1, são apresentados os valores médios da umidade inicial das fatias de limão e de suas frações.

Tabela 1 - Umidades iniciais médias das fatias e frações do limão.

\begin{tabular}{|l|c|}
\hline \multicolumn{1}{|c|}{ Materiais } & $\begin{array}{c}\mathrm{X}_{\circ} \\
\left(\mathrm{g} \mathrm{H}_{2} \mathrm{O} / \mathrm{g} \mathrm{sol} . \text { seco }\right)\end{array}$ \\
\hline Fatias & $5,32 \pm 0,14$ \\
\hline Endocarpo fatiado & $5,19 \pm 0,34$ \\
\hline Epicarpo & $1,92 \pm 0,31$ \\
\hline Mesocarpo & $1,94 \pm 0,16$ \\
\hline
\end{tabular}

Observou-se que as umidades variam bastante em cada fração. As fatias e o endocarpo fatiado apresentaram as maiores umidades iniciais, em torno de $5 \mathrm{~g} \mathrm{H}_{2} \mathrm{O} / \mathrm{g}$ sólido seco. Já nas frações do epicarpo e mesocarpo, as umidades inicias em base seca foram cerca de três vezes inferiores se comparadas às frações contendo o suco. 
Nas Figuras 3(a) e 3(b), são mostrados os dados de adimensional de umidade (MR) em função do tempo e a taxa de secagem em função da umidade para a secagem da amostras 1 e 2 das fatias do limão Tahiti, na temperatura de $50{ }^{\circ} \mathrm{C}$. É possível notar que houve boa reprodutibilidade dos dados experimentais. O tempo necessário para atingir a umidade de equilíbrio dinâmica foi de 1190 minutos. Nas curvas de taxa de secagem em função da umidade mostradas na Figura 3(b), é possível verificar que o processo se inicia com taxas de aproximadamente 0,004 ( $\mathrm{g} \mathrm{H}_{2} \mathrm{O} / \mathrm{g} \mathrm{ss} \cdot \mathrm{min}$ ), aumenta até um máximo de aproximadamente 0,014 ( $\mathrm{g} \mathrm{H}_{2} \mathrm{O} / \mathrm{g}$ ss·min), para umidade $\mathrm{MR}=0,6$ e a partir daí decresce até o final da secagem. $\mathrm{O}$ aumento da taxa observado no início da secagem deve-se ao período inicial de aquecimento das amostras. $\mathrm{O}$ período de secagem à taxa constante não foi observado, assim como relatam outros autores que estudaram a secagem de produtos alimentícios (PARK, et. al., 2001).

(a)

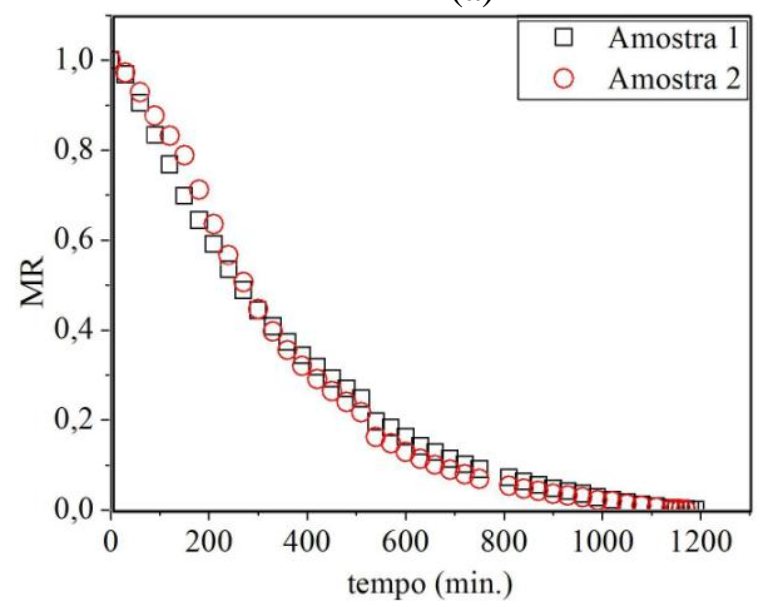

(b)

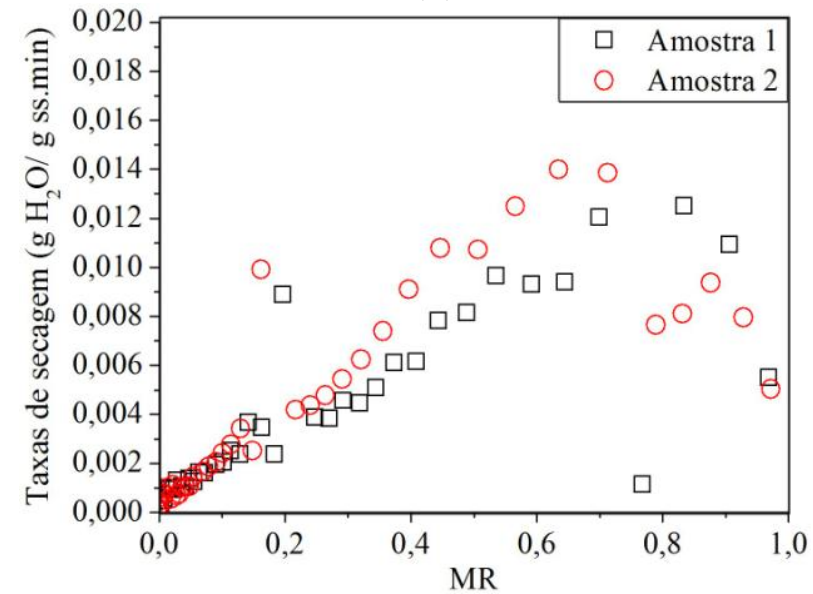

Figura 3 - Adimensional de umidade em função do tempo (a) e taxa de secagem em função de MR (b), para secagem de fatias de limão Tahiti, na temperatura de $50{ }^{\circ} \mathrm{C}$.

A perda de umidade observada nas fatias ao final do processo alcançou $84 \%\left(\mathrm{X}_{\mathrm{bu}}\right)$. Pode-se observar, nas fotos da Figura 4 que ocorreu um significativo encolhimento das fatias ao final da secagem. Nota-se também que as fatias secas sofreram pouco escurecimento e mantiveram o formato, apesar do encolhimento observado na espessura e diâmetro das fatias.
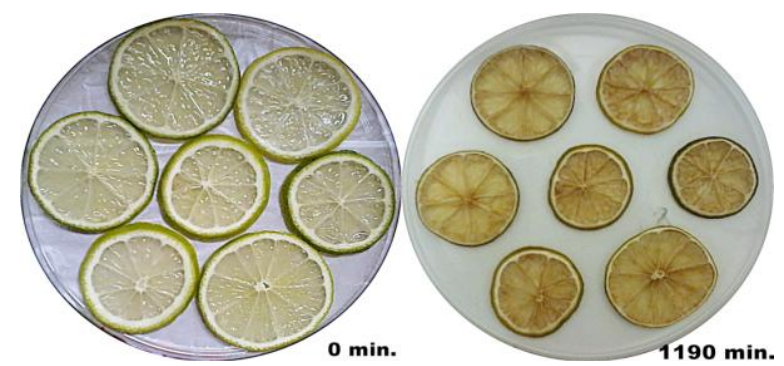

Figura 4 - Fatias de limão in-natura e após a secagem

Também foram realizados dois ensaios para cada uma das frações do limão Tahiti e as 
reprodutibilidades obtidas foram aceitáveis em todas elas, de forma que a partir daqui serão apresentados e discutidos os resultados baseados em valores médios.

As curvas de MR em função do tempo de secagem para o endocarpo fatiado são apresentadas na Figura 5, cuja cinética de secagem mostra que foram necessários 580 minutos para atingir a umidade de equilíbrio dinâmica, cerca de metade do tempo consumido para a secagem das fatias. Esta fração do limão Tahiti possui umidade inicial próxima à das fatias, e não possui as camadas de casca nas suas bordas, que foram separados, o que muda a área exposta e favorece a remoção de umidade. As taxas atingiram um valor máximo de $0,039\left(\mathrm{~g} \mathrm{H}_{2} \mathrm{O} / \mathrm{g} \mathrm{ss} \cdot \mathrm{min}\right)$, bem superior ao máximo observado na secagem das fatias. Também neste caso a secagem ocorreu predominantemente no período decrescente.

(a)

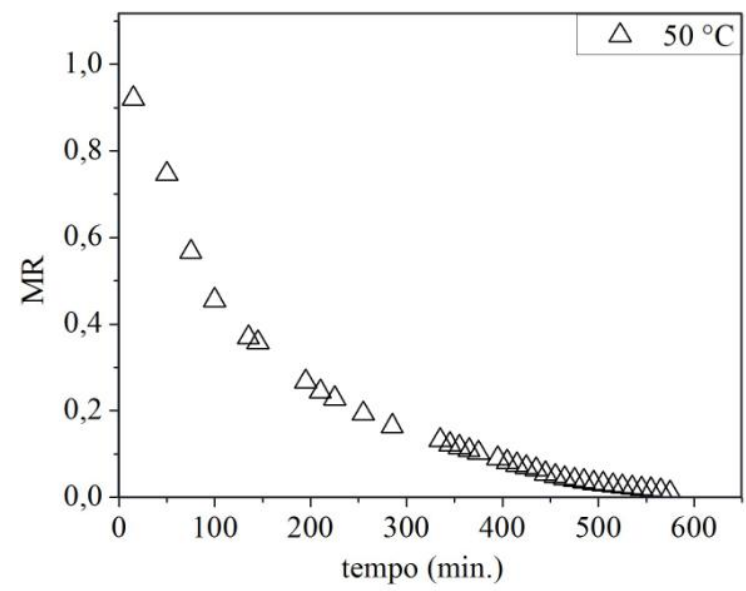

(b)

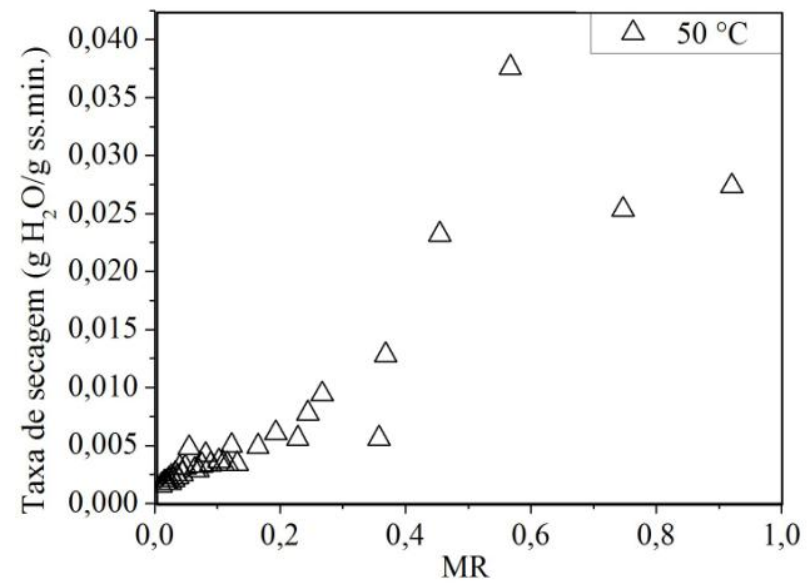

Figura 5 - Adimensional de umidade em função do tempo (a) taxa de secagem em função de MR (b), para o endocarpo fatiado na temperatura de $50{ }^{\circ} \mathrm{C}$.

As curvas de MR em função do tempo para a secagem do epicarpo e do mesocarpo são apresentadas nas Figura 6(a) e 6(b), respectivamente. É possível observar que o tempo necessário para atingir a umidade de equilíbrio dinâmica foi de 250 minutos para o epicarpo, e 230 minutos para o mesocarpo. Em média, a secagem dessas frações ocorreu em tempos cerca de cinco vezes inferior ao das fatias. Além do menor conteúdo de umidade inicial destas frações, a composição e a estrutura também diferem bastante em relação ao endocarpo, o que altera a resistência do meio ao transporte de umidade.

As curvas de taxa de secagem em função de MR são apresentadas nas Figuras 6(c) e 6(d). As taxas de secagem máximas para estas frações foram iguais a aproximadamente 0,025 (g $\mathrm{H}_{2} \mathrm{O} / \mathrm{g}$ ss.min), e ao se comparar com a maior taxa observada na secagem do endocarpo fatiado, onde predomina a presença das vesículas contendo o suco, nota-se que o valor para o epicarpo e o mesocarpo foi cerca de $36 \%$ inferior. As curvas de taxa de secagem do epicarpo e mesocarpo apresentam majoritariamente o período decrescente, sendo que na secagem do mesocarpo foi observada a variação característica do aquecimento inicial da amostra para altos valores de MR. 
(a)

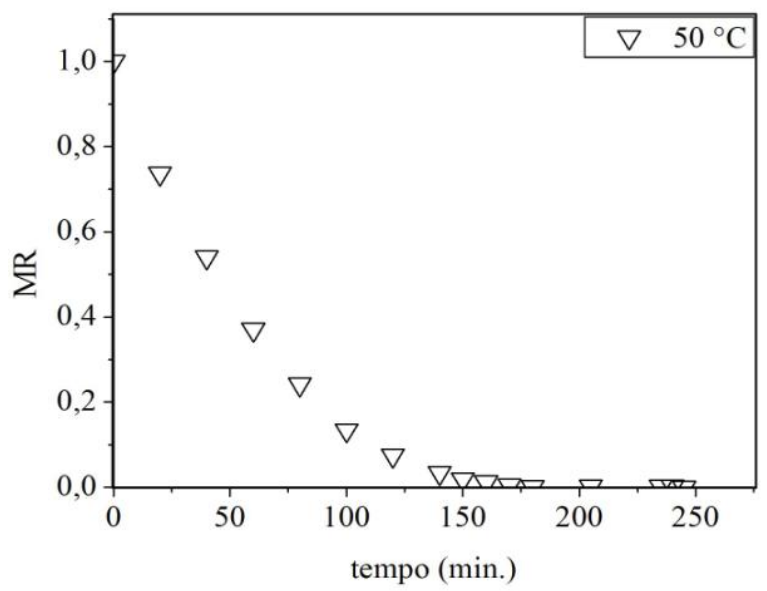

(c)

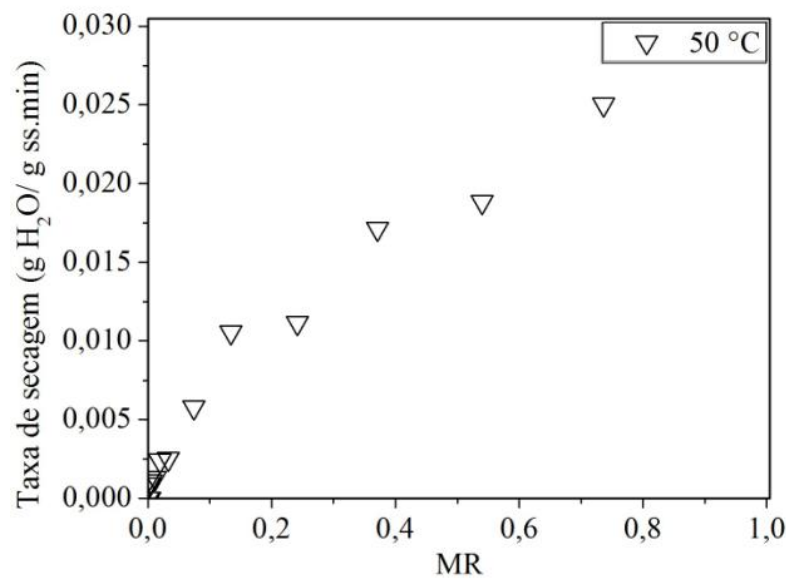

(b)

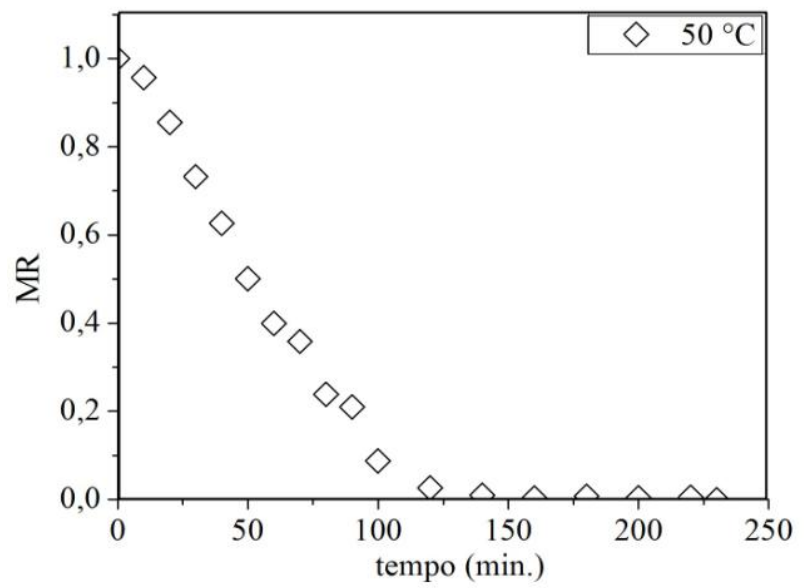

(d)

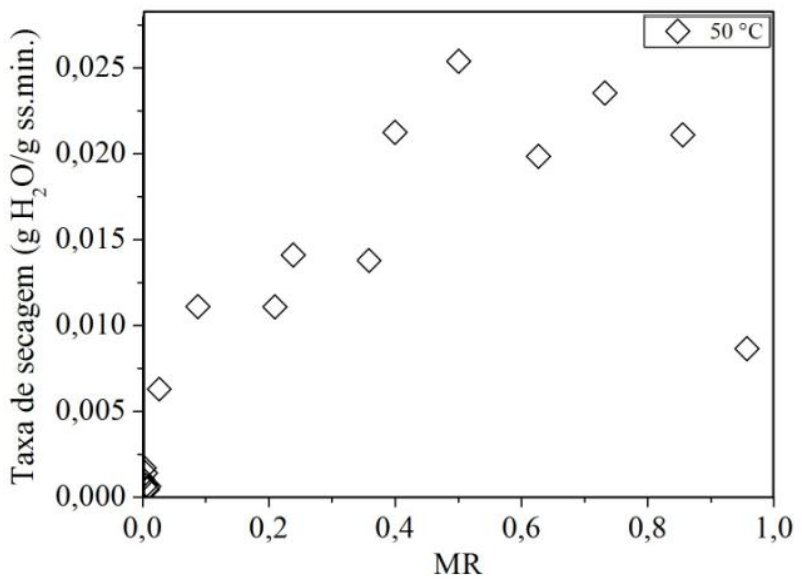

Figura 6 - Umidade adimensional em função do tempo para (a) epicarpo, e (b) mesocarpo; taxa de secagem em função de MR (c) epicarpo e (d) mesocarpo, na temperatura de $50{ }^{\circ} \mathrm{C}$.

Uma análise comparativa das curvas de cinética de secagem para a fatia de limão e suas diferentes frações pode ser efetuada com base nos resultados apresentados na Figura 7.

Nota-se que o epicarpo e o mesocarpo apresentaram cinéticas de secagem similares, isoladamente foram as frações em que a umidade foi removida mais rapidamente, enquanto a redução de umidade do endocarpo fatiado foi intermediária. As taxas de secagem das fatias são menores do que as observadas para as frações individuais. A fatia de limão é composta pelas três frações, sendo que cada uma contribui para a cinética de secagem resultante. Uma possível justificativa para o fato da cinética de secagem das fatias ser mais lenta do que as observadas para as frações isoladas é o fato de que, na fatia, as diferentes partes estão interligadas em uma estrutura única, e a resistência à perda de umidade é uma combinação mais complexa do que uma simples média das resistências observadas nas frações individuais e isoladas. 


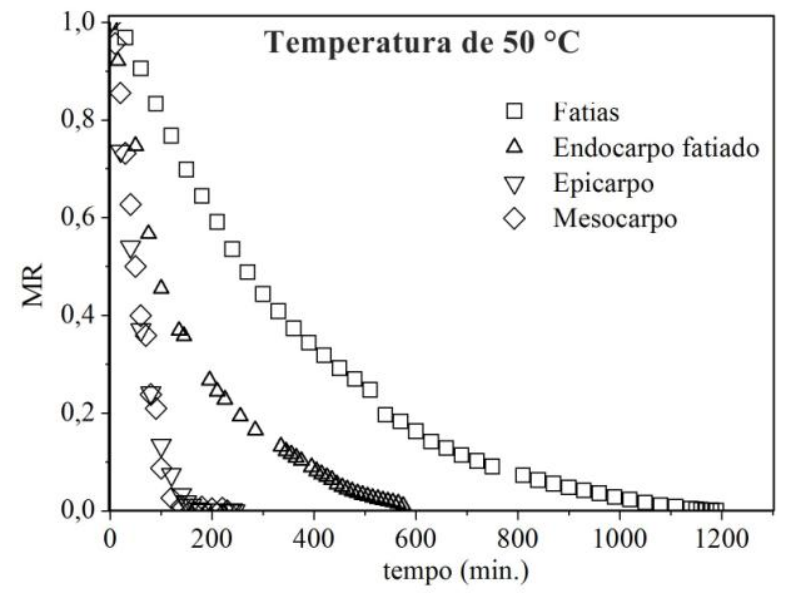

Figura 7 - Umidades adimensionais em função do tempo (a) para temperatura de $50{ }^{\circ} \mathrm{C}$ e (b) para a temperatura de $60{ }^{\circ} \mathrm{C}$.

Os experimentos de secagem das fatias e de todas as frações também foram realizados na temperatura de $60{ }^{\circ} \mathrm{C}$. Como previsto, o aumento da temperatura provocou um aumento nas taxas e o tempo de secagem foi reduzido em cerca de $33 \%$, como pode ser observado na figura 8 . Os resultados para as frações individuais foram qualitativamente semelhantes, e por concisão não serão apresentados aqui.

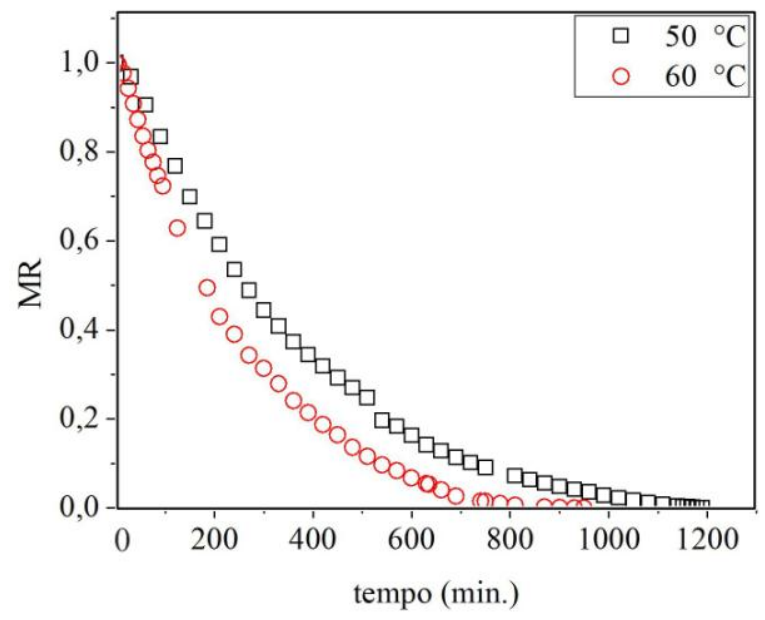

Figura 8 - Umidade adimensional em função do tempo para fatias do limão Tahiti na secagem a temperaturas de $50{ }^{\circ} \mathrm{C}$ e $60^{\circ} \mathrm{C}$.

Nesta etapa do trabalho estão sendo obtidos dados experimentais para a secagem do limão, sendo ainda necessária a obtenção de dados em outras temperaturas e será avaliado o ajuste a modelos empíricos e semi-empíricos para estimativa das taxas de secagem e o efeito da temperatura no processo. 


\section{CONCLUSÕES}

Com base nos resultados obtidos, é possível concluir que a secagem de cada uma das frações ocorre com taxas diferentes, e em todas elas a secagem ocorreu predominantemente no período de taxa decrescente. Verificou-se que o endocarpo fatiado foi a fração que isoladamente apresentou taxas de secagem mais altas, em comparação com o epicarpo e mesocarpo. A secagem das fatias apresentou cinética mais lenta do que as partes individuais, indicando que a resistência à remoção de umidade oferecida pela estrutura combinada das diferentes partes do limão na fatia é maior do que uma média das resistências nas frações isoladas. Nas condições avaliadas, o aumento da temperatura de $50{ }^{\circ} \mathrm{C}$ para $60{ }^{\circ} \mathrm{C}$ provocou redução de aproximadamente $33 \%$ no tempo de secagem das fatias. Em ambas as temperaturas, foi observado encolhimento das fatias.

\section{NOMENCLATURA}

$\begin{array}{lll}\text { bs } & \text { Base seca } & \\ \text { bu } & \text { Base úmida } & \\ \text { MR } & \text { Razão de umidade } & {[-]} \\ \text { X } & \text { Conteúdo de umidade } & {[-]} \\ \text { ss } & \text { Sólido seco } & \\ 0 & \text { Instante inicial } & \\ \text { eq } & \text { Equilíbrio } & \\ \mathrm{t} & \text { Instante t } & \end{array}$

\section{REFERÊNCIAS}

FONSECA, R. B. F. Identificação das substâncias voláteis em lima ácida (Citrus latifolia, Tanaka), cv. Tahiti, obtida por cultivo convencional e cultivo biodinâmico, 2007. 66 f. Dissertação (Mestrado), Instituição de Nutrição Josué de Castro, UFRJ, Rio de Janeiro.

MILLEZI, A. F. et al. Caracterização e atividade antibacteriana de óleos essenciais de plantas condimentares e medicinais contra Staphylococcus aureus e Escherichia coli. Rev. Bras. de Plan. Med., Campinas, v. 15, n. 3, p. 373-379, 2013.

PARK, K. J; YADO, M. K. M.; BROD, F. P. R. Estudo de Secagem de Pera Bartlett (pyrus SP.) em fatias. Cienc. Tecnol. Aliment., Campinas, v. 21, n.3, p. 288-292, 2001.

VIANA, D. S. Lima ácida (Citrus latifolia, Tanaka), cv. Tahiti, de cultivos convencional e orgânico biodinâmico: avaliação da capacidade antioxidante dos sucos in natura e clarificados por membranas de microfiltração, 2010. 100 f. Dissertação (Mestrado), Faculdade de Farmácia, UFRJ, Rio de Janeiro.

ZIENA, H. M. S. Quality attributes of bearss seedless lime (Citrus latifolia Tanaka) juice during storage. Food Chem., v. 71, 2000, p. 167-172. Disponível em: <http://w ww.sciencedirect.com/science/article/pii/S0308814600000649\#>. Acesso em:11 out. 2013. 